\title{
Walkability and Its Relationships With Health, Sustainability, and Livability: Elements of Physical Environment and Evaluation Frameworks
}

\author{
Abdulla Baobeid, Muammer Koç and Sami G. Al-Ghamdi* \\ Division of Sustainable Development, College of Science and Engineering, Hamad Bin Khalifa University, Doha, Qatar
}

Urban sprawl and increasing population density in urban centers create the challenge to finding ways of sustainable transportation solutions that preserve the convenience of residents while reducing emissions. Therefore, walkability is a core urban design element because of being advantageous onto three fronts: health, livability, and sustainability. Adopting walkability as urban solution relieves conceptual and practical tensions between the individualistic interests manifested in the desire to own and use private cars, and the need to reduce transportation-based consumption. This review advocates that long-term health benefits from walking and physical activity are the premier incentive to repurpose our

Edited by:

Shu-Li Huang,

National Taipei University, Taiwan

Reviewed by:

Ying-Chieh Lee,

National Chung Hsing University,

Taiwan

Shenjun Yao,

East China Normal University, China

${ }^{*}$ Correspondence:

Sami G. Al-Ghamdi salghamdi@hbku.edu.qa

Specialty section: This article was submitted to

Urban Science,

a section of the journal Frontiers in Built Environment

Received: 06 June 2021

Accepted: 26 August 2021 Published: 30 September 2021

Citation:

Baobeid A, Koç M and Al-Ghamdi SG (2021) Walkability and Its Relationships With Health, Sustainability, and Livability: Elements of Physical Environment and Evaluation Frameworks. Front. Built Environ. 7:721218. doi: 10.3389/fbuil.2021.721218 cities to be more sustainable and more walking friendly, and spark behavioral change into reducing car dependency for all daily transportations. The review inspects physical elements of the built environment that make the walking trip feasible and desirable, such as connectivity, accessibility, and closeness of destination points, presence of greenness and parks, commercial retail, and proximity to transit hubs and stations. Hence, this review explores a few popular walkability evaluation indices and frameworks that employ subjective, objective, and/or distinctive methods within variant environmental, cultural, and national context. There is no unified universal standardized walkability theory despite the need for rigorous evaluation tools for policy makers and developers. Furthermore, there is a lack of emphasis on air quality and thermal stress while approaching walkability, despite being important elements in the walking experience. Research opportunities in the field of walkability can leverage location tracking from smart devices and identify the interaction patterns of pedestrians with other transportation modes, especially for those with fundamental movement challenges such as wheelchair users.

Keywords: walkability evaluations, health, sustainability, livability, built environment

\section{INTRODUCTION}

Historically, walking has been the main mode of transportation in urban areas. That changed with the rapid urbanization and mass introduction of cars in the 1950s and the subsequent population growth in suburbanite areas around the major cities. This created an expansion pattern known as known as urban sprawl, in which large swathes of urban populations move to the outskirts and suburbs of their cities, which are designed to have low-density housing, and a lifestyle dependent on 
private automobiles due to the single land-use and the scattering of the daily destinations (Glaeser and Kahn, 2004). Since then, most planning focused on creating the space for motorized transportation, especially highways connecting sparse urban centers and neglected active transportation modes such as walking and biking. Only with the oil crisis of the 1970s, and the expansion of high-rise buildings did urban developers begin emphasizing the importance of walkability, particularly for those who travel by public transportation (Tribe, 1976; Lo, 2009; Roe and Aspinall, 2011; Forsyth, 2015). Today, walking and walkability is increasingly becoming a central theme in urban planning, partially in response to public demand and the search for sustainable urban development. The need to reduce air pollution and carbon emissions per capita, the exhaustive traffic stress on urban centers, and an increasing environmental awareness by city dwellers have advanced public support for nonmotorized, active transportation modes. Health studies examining physical activity cite walking and biking as measures that facilitate physical rehabilitation and mitigate modern chronic diseases such as obesity, diabetes and hypertension, and mental health and depression (Barton et al., 2009; Johansson et al., 2011; Roe and Aspinall, 2011; Mackenbach et al., 2014). Walkability and walking are closely entwined with the concepts of the livability of local communities as well as sustainability and its three pillars: the economic, social, and environmental.

In broad terms, walkability is defined by quality of which the built environment enables the mobility of pedestrians. Pedestrians traditionally are defined as the individuals traveling by foot, but it has recently been expanded to include those who use wheelchairs or other assistive devices (Lo, 2009). Walkability, as we demonstrate throughout this review, is viewed to serve multiple aspects of life, and thus is measured and assessed through different variables, such as the pedestrian sidewalks, accessibility to amenities, and environmental conditions, and still a subject of debate, and different prioritization approaches to the competing factors in the built environment (Southworth, 2005; Forsyth, 2015).

Several physical environments must be analyzed to create a walkable urban space. Some of these concern the pedestrian infrastructure in the finer, smaller scale; the sidewalks have to be accessible, direct, connected, safe, comfortable, shaded, and well maintained for the full spectrum of pedestrians (Frackelton et al., 2013; Aghaabbasi et al., 2018). Sidewalks must be designed to allow pedestrians to reach transit points of public transport (Jeffrey et al., 2019). The general urban characteristics on the larger scales influence walkability. An appropriate population density lends itself into an economically vibrant ambience and this urban vibrancy is echoed in the presence of amenities such as schools, shops, restaurants, offices, parks, and gyms that encourage people to walk to go to their daily activities. The optimal population density is usually reflected in the density of road intersections and small lengths of urban blocks, allowing pedestrians to take shorter and more direct paths to their destinations (Frank and Engelke, 2001; Saelens et al., 2003). The methodology of measurement, and the relative weighting of each individual factor differs according to the local context and its priorities.
This review investigates the role of walkability as a core urban feature designed to link and improve upon three basic needs, 1 -the health of residents, 2-livability and quality of life for members of the community, and 3-long-term sustainability with its three pillars, the environment, economy, and society. The review aims at adding to the discourse of walkability studies by shedding light on walkability evaluation frameworks, and their evaluation of the major elements of the built physical environment through a narrative literature review. The review concludes by identifying aspects that profoundly influence the pedestrian walking feasibility yet are not highlighted enough in walkability audits and frameworks, especially in the light of the three basic needs of health, livability, and sustainability. Improving walkability evaluation frameworks will guide future actions such as correction and retrofitting existing infrastructure, and development of walking-friendly environments for pedestrians within inclusive, sustainable, and livable neighborhoods that enable residents to walk and exercise in a manner that serves their health and well-being.

The case against walkability in modern design: value of property in suburbs; desire of privacy; search for more.

\section{WALKABILITY RELATIONSHIP WITH HEALTH, SUSTAINABILITY, AND LIVABILITY}

In the heart of the modern living experience, lie two largely intersecting yet occasionally contrasting concepts of sustainability and livability. Livability can be defined as the combined objective influences on a community's quality of life. Livability is hypothetically reflected on the subjective satisfaction of the community with their surrounding environment, while sustainability is concerned with the balance between the social, economic, and environmental facets of development as well as the preservation and regeneration of resources for both present and future generations. Livability is concerned with present, immediate needs, while sustainability is concerned with the overall longterm wellbeing of humanity and Earth. These two concepts must be reconciled and colligated to advance a happy, comfortable way of living (Chazal, 2010; Gough, 2015); In addition, health awareness has been a strong incentive for many to support the agenda of sustainability and livability; however, this review makes the distinction between the health, sustainability, and livability despite the large overlaps between the three goals. This distinction is critical to address context-specific issues should they arise. Figure 1 explores how walkability serves to individual health, the community livability on the scale, and the sustainability.

\section{Walking and Health}

Walking as a low-intensity physical activity is associated with healthier populations since it contributes to lower rates of obesity, diabetes, and cardiovascular diseases (Hu et al., 1999; Gregg et al., 2003; Smith et al., 2007). The negative associations between nonchronic diseases and physical activity have been well documented in many studies. Walking as a physical activity is associated with 


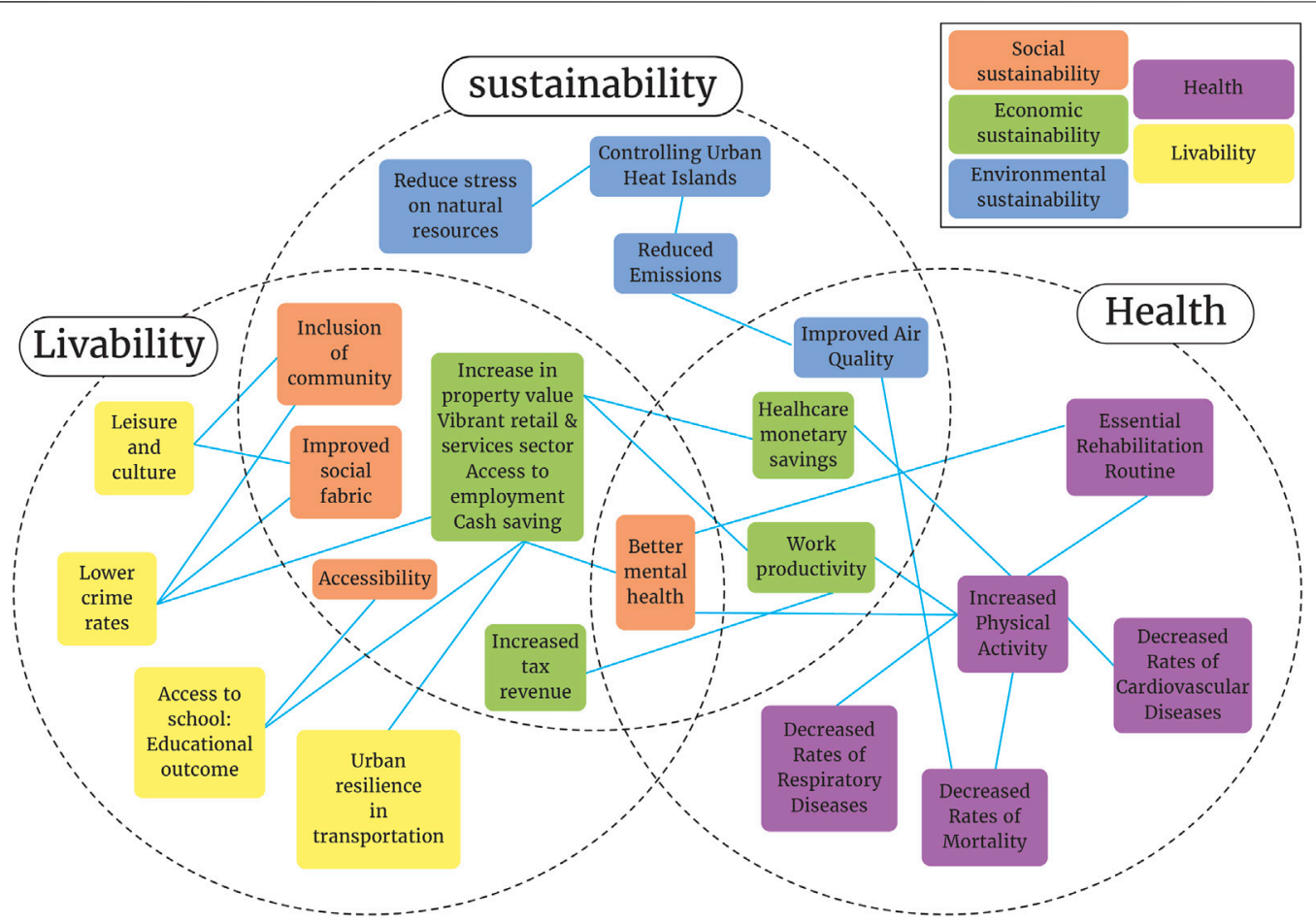

FIGURE 1 | Framework to analyze walkability relationship with health, sustainability, and livability.

lower Body Mass Index (BMI), controlled blood pressure, and lower rates of diabetes (Sarkar et al., 2018; Howell et al., 2019). Neighborhood walkability is also associated with lower respiratory diseases rates such as asthma in children (Simons et al., 2018).

A study by Saint Maurice et al. (2020) on adults in the United States drew the correlation between higher daily step count and average all-causes mortality rates. The mortality rate for those above 65 years old who walked for 2,000 steps per day was found to be 78 per 1,000 as opposed to the mortality rate of 12 per 1,000 for those who walked 10,000 steps per day. Walking is considered a safe training activity to improve cardiovascular health in general (Houle et al., 2011). More intense forms of walking further enhance benefits to the peripheral cardiovascular system.

Walking is considered a pain-free activity that does not require recovery time nor special equipment or specific training, which makes it a recommended form of physical activity for those in rehabilitation from illness or injury. Walking is often recommended for elders suffering from osteoporosis (Pereira Neto et al., 2018). Walking has also proven to be a safe activity for those recovering from cardiovascular diseases (Martinez et al., 2009; Novaković et al., 2019) or chronic musculoskeletal pain (O'Connor et al., 2015). Moderate walking additionally has been discovered to help cancer patients sleep (Chiu et al., 2015).

Walking is even associated with improved mental health. There is in particular a strong negative correlation between walking and depression symptoms in older adults (Mobily et al., 1996). The ability to engage in a physical activity such as walking compensates for the diminishing sense of control and dwindling roles for older people. The social dimension of walking helps to maintain social skills and connectivity, and the ability to do daily shopping helps to maintain a sense of purpose.

Since it is an easy activity, walking is well-liked by adults regardless of their ethnic or demographic background (Roe and Aspinall, 2011). In modern lifestyles, walkability has become an indicator of urban livability and quality of life. Walking comfortably for small and reasonable distances to engage in daily activities contributes to increased levels of physical activity and better livability.

\section{Walkability, Livability, and The Connection With Sustainability}

The core of the conflict and tension between sustainability and livability is that many of the instantaneous needs and desires of the population to make life quality better, have unsustainable consequences on the long term. While recent livability indices such as Economist Intelligence Unit's Livability Ranking and Mercer's Quality of Living Reports are increasing giving more attention to environmental aspects through a mixture of objective parameters that describe the urban environment and life quality parameters, subjective parameters describe resident's satisfaction (Howley et al., 2009; Tomalty and Mallach, 2015).

For a community to be considered livable, it must maintain acceptable levels of equity, social stability, social engagement, crime rates, and nurture a shared sense of local culture. Economic 
TABLE 1 | Resolving conceptual and practical tensions between livability and sustainability (Lauf et al., 2014; Ruth and Franklin, 2014; Gough, 2015; Newell et al., 2018; Martínez-Bravo et al., 2019).

Domain Sustainability Livability

Geographic scale of Global or national scale, with holistic and action
Localities: municipalities and Neighborhood scale
Tension resolution

Determining the boundaries of authorities Livability needs sustainability to create national as well as global policies Sustainability needs livability to influence behavior at the micro level

\begin{tabular}{lll}
\hline Timeframe & Long time, decades, or generations & Short time, months, or years \\
Concerned with the impact on the future & Concerned with the impact on the present
\end{tabular}

Concerned with the impact on the future

Concerned with the impact on the present

Tension between present and future needs. Sustainable livability can demonstrate benefits Livability proves the practical positive results of sustainability policies; for example, improvements toward cleaner air in urban areas generate wider support than air quality improvements on a global scale

\begin{tabular}{lll}
\hline Organizational & Policies and actions are difficult to reverse and & Policies and actions can be quickly reversed and \\
structure & correct due to complex organizational & corrected due to simpler organizational \\
& structures & structures
\end{tabular}

Economic nudges Economic incentives and nudges are harder to Economic incentives and nudges are easier to manage and implement due to the large economic scale involved. Incentives or fines might be insensitive to local contexts

Trickling down sustainability-oriented policies and regulations to the local levels

Implementing and managing more economic incentives on the local level with an easily measurable impact on livability and sustainability
Opposing undesirable national or global trends might be difficult

Dynamic view driven by the needs and preferences of the populace economic, and environmental aspects. It should not fluctuate with changes of public opinions

Decision making context Some of the corrective actions pertaining to

Expedience of corrective actions regulatory bodies take longer time, and more complex with many extrinsic correlations, mainly due to structural economic significances
Corrective actions are faster and easier, while many of the corrective actions serve sustainability goals, the main driver is the satisfaction of the population
Transportation modes Ideally, sustainability encourages low-carbon transportation modes, such as public transportation; foot, bike, or public transportation, and discourages private transportation

Air pollution Sustainability often calls for reducing the emissions per capital to achieve a global reduction on a global scale. Therefore, more densely populated areas theoretically reduce emissions per capita due to pooling resources

\begin{tabular}{ll}
\hline Consumption & $\begin{array}{l}\text { Sustainability calls for reducing the use of } \\
\text { natural resources, which might regulate the } \\
\text { availability and affordability of consumer } \\
\text { products }\end{array}$ \\
\hline Waste management & $\begin{array}{l}\text { Reduction of waste per individual, collectable, } \\
\text { and separable waste that is easy to process } \\
\text { and recycle }\end{array}$
\end{tabular}

A mix of transportation modes that prioritize convenience at different circumstances. However, the use of private cars is coveted due to freedom of movement, privacy, and social connotations

Increasing population density beyond certain thresholds leads to unhealth concentration of emissions, which negate the health benefits from walkability, which is often not noticed until it exceeds extreme levels such as strong smog. Although the compactness makes many economic activities more accessible and commercial scene more vibrant

Continuous affordability and availability of products are associated with mass production practices that might not necessarily be sustainable

Concentrated waste of large quantities which is easier to collect, yet it must be transported to
An example of this resolution is economic incentives to install residential solar energy systems in areas suffering from excessive load on the grid

Developing sustainability strategies with built-in resilience and flexibility to respond to evolving the patterns and trends

Rely on livable sustainability for faster mitigative corrective actions while building the inclusive strategy of sustainability. Examples include improving walkability and air quality in densely populated zones, or establishment of small and medium recycling facilities on the local level to handle waste from residential areas, faster than relying on mega recycling projects. Another example is expansion of pedestrian spaces on the expense of vehicles in certain shopping areas

Seeking a balanced transportation mix to ensure accessibility with the minimal emissions possible

Controlling transportation emissions, decreasing vehicle transportation of the resident's movement by improving walkability and accessibility. Expanding the green cover of the city
Reconciling sustainability with productions methods, while increasing the efficiency of consumption processes

Holistic management approaches through strategies such as circular economy

(Continued on following page) 
TABLE 1 | (Continued) Resolving conceptual and practical tensions between livability and sustainability (Lauf et al., 2014; Ruth and Franklin, 2014; Gough, 2015; Newell et al., 2018; Martínez-Bravo et al., 2019).

\begin{tabular}{|c|c|c|c|}
\hline Domain & Sustainability & Livability & Tension resolution \\
\hline & & $\begin{array}{l}\text { appropriate locations, mostly outside the urban } \\
\text { areas, to process and recycle }\end{array}$ & \\
\hline Global warming & $\begin{array}{l}\text { Condensing population theoretically leads to } \\
\text { efficient pooling of resources, hence, lower } \\
\text { emissions per capita, as energy intensive } \\
\text { activities are sourced outside urban boundaries }\end{array}$ & $\begin{array}{l}\text { Urban heat islands increase the need for air } \\
\text { conditioning, which consume high amounts of } \\
\text { energy }\end{array}$ & $\begin{array}{l}\text { Increasing vegetation, decreasing traffic to } \\
\text { reduce the severity of urban heat islands. } \\
\text { Improving accountability of consumption } \\
\text { activities }\end{array}$ \\
\hline $\begin{array}{l}\text { Practical } \\
\text { significance }\end{array}$ & $\begin{array}{l}\text { Practical impacts are indirect and only visible on } \\
\text { the long term }\end{array}$ & $\begin{array}{l}\text { Practical impact is direct and clear on the short } \\
\text { term }\end{array}$ & $\begin{array}{l}\text { Sustainable livability as a concept that } \\
\text { reconciles the needs to higher quality of life and } \\
\text { utilization of resources while minimizing stress } \\
\text { on environment }\end{array}$ \\
\hline $\begin{array}{l}\text { Long term health } \\
\text { effects }\end{array}$ & $\begin{array}{l}\text { Health is not clearly pronounced as one of the } \\
\text { three pillars of sustainability. However, it is the } \\
\text { Goal } 3 \text { of the UN's Sustainable Development } \\
\text { Goals. Environmental pollution has negative } \\
\text { impact on health }\end{array}$ & $\begin{array}{l}\text { Indicators of obesity and diabetes are } \\
\text { considered in livability indices, where lack of } \\
\text { access to locations on foot results in a lack of } \\
\text { physical activity } \\
\text { However, deteriorating environmental indicators } \\
\text { due to unmanaged population density might } \\
\text { negate these benefits }\end{array}$ & $\begin{array}{l}\text { Clean environment, clean air, and space to } \\
\text { engage in physical activity are necessary for } \\
\text { healthy population. Walkability and walking are } \\
\text { major features for sustainable livability }\end{array}$ \\
\hline
\end{tabular}

activity in a livable community should be robust enough to generate income and high quality of life. Housing must be affordable and comfortable, and the flow of energy, goods, food, and services should be uninterrupted, and markets should be easily accessible. Basic services such as water, sewage, electricity, and communications should be well established, and fundamental infrastructure such as roads and lighting should be built to serve the community (Ruth and Franklin, 2014; Lukuman et al., 2017). Walkability is not the only defining factor in determining social characteristics such as crime rates or school safety, and it is easily overruled by the negative aspects of historic discriminatory racial, gendered, and socioeconomic patterns that take place in many urban developments; in these contexts, crime and sense of insecurity emerge as barriers to walking (Zhu and Lee, 2008; Comer and Greene, 2015; Cowen et al., 2019).

The environment should also be cared for in a livable community; there should be clean, high-quality air, effective waste management, and clean drinking water. Parks, green spaces, and street vegetation are also essential elements to provide in venues for leisure as they improve mental health and the environment (Ruth and Franklin, 2014). Unfortunately, some of these basic elements of livability are associated with a consumeristic facet to good quality of life, and require the use of natural resources, which come into conflict with sustainability principles.

It is noticed that there is an increasing awareness of impact of sustainability on the quality of life, and progressively reflected on livability indices, reflecting work in recent decades to reconcile the two concepts. A main impetus of this reconciliation has been public health concerns, many of which are discussed in the previous Walking and Health. In addition, an increasing awareness of the climate crisis and global warming has garnered support for regulations and measures to push for more sustainability. The tensions between the concentrated urban instantaneous livability versus the macro and long-term sustainability are deconstructed and presented with successful resolution suggestions in Table $\mathbf{1}$.

Walking is the heart of sustainability; it is humanity's first mode of transportation, a transportation mode that does not require external energy sources and that helps to keep people healthy, happy, and active. Walkability, which measures how hospitable a place is for walking, influences sustainability in economic, social, and environmental terms. The ability to walk to different nearby destinations is associated with public satisfaction of transportation arrangements (Shamsuddin et al., 2012).

\section{Sustainability and Walkability}

Walkability is often the economic, environmental, and the social with the limited resources of energy, space, environment, and water. Basic features of the relationship between walkability and the three aspects of sustainability are demonstrated in Figure 2. The classification of sustainability into these three types is well established in the United Nations literature and has been the basis to develop the Sustainable Development Goals (SDGs).

\section{Environmental Sustainability}

Building walkable communities contributes to reducing automobile-based transportation. Urban centers with higher population densities and walkable communities are associated with lower overall carbon emissions per capita than their rural and suburban surroundings. Some of the main benefits of walkability are briefly discussed here.

\section{Reduction in Transportation Emissions and Consumption of Resources}

While this drop in emissions per capita can be attributed largely to the absence of agricultural and industrial activities, a sizable 

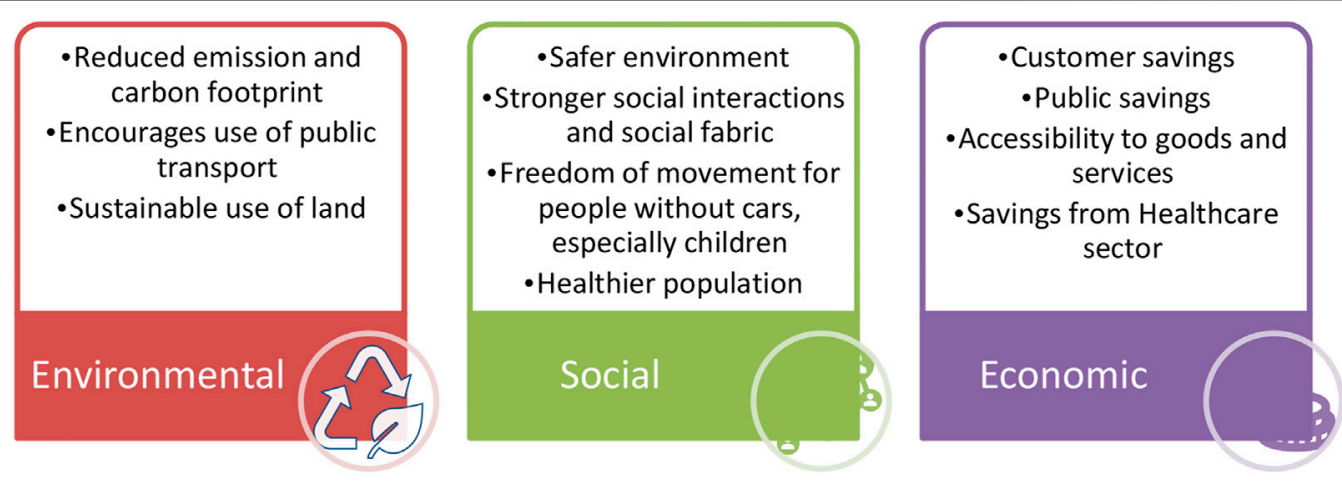

FIGURE 2 | Relationship of walkability with sustainability aspect. Source: Authors.

portion of the reduction can be attributed to the shorter transportation commutes and accessibility of goods and services (Poom and Ahas, 2016). To achieve more accurate measurements, recent studies have focused on the measurement of alterations in carbon footprint caused by behavioral changes. A study in London, United Kingdom, indicated that nearly $42 \%$ of short car trips of less than 3 miles could be substituted by walking or biking; the estimated $\mathrm{CO}_{2}$ emissions reduction in such a case was measured at $2.8 \mathrm{kgCO}_{2} \mathrm{e}$ per person per week, an equivalent of $10.9 \%$ of all car travel. Given the purpose of traveling and other factors, a realistic shift via the project connect2 from carbon intensive transportation to walking or biking was estimated to reduce short trip travel by $41 \%$, or $1.15 \mathrm{kgCO}_{2} \mathrm{e}$, which would account for $4 \%$ of all car travel (Neves and Brand, 2019). Such reduction might be even greater when put into the context of countries with larger average car emissions than the United Kingdom. Similar efforts to promote walking and biking in New Zealand led to a reduction of at least $1.6 \%$ of emissions after 3 years as well as a drop in overall vehicles per household (Keall et al., 2018). However, there are not many examples that establish a well-calculated quantitative link between $\mathrm{kgCO}_{2} \mathrm{e}$ emission reduction and the promotion of walking and biking.

\section{Air Pollution}

Associations between walkability and air pollution are not direct. More congested city centers tend to be more walkable but have higher air pollution and suburbs have low walkability and low air pollution, but the regions in the middle tend to have low air pollution and high walkability. Studies show that air pollution impacts the quality of health benefits achieved through walking, and other studies question the risks from exposure to particulate matters. Finding the balance between pollution and population density is an active goal for good urban planning and is a discourse tied to questions about socioeconomic equity (Marshall et al., 2009; James et al., 2015; Hankey et al., 2017).

\section{Social Sustainability}

Social sustainability can be defined as the state and process of enhancement in quality of life. Social sustainability is influenced by physical factors such as the climate and ecological environment, natural resources, and built environment, as well as non-physical factors such as the richness of demographic backgrounds, diversity in educational and professional backgrounds, and the network of interpersonal relations and communications between the members of a community. Heavily car-oriented subdivisions negatively influence the social capital and the possible social interactions on the neighborhood level (Leyden, 2003).

\section{Social Inclusion for People With Disabilities}

The social benefits from walkability are a major driver for its adoption, walkability creates a hope for more social inclusion within communities, which was reflected into the modern definitions of a pedestrian to include those transporting by wheelchair. This is codified in many countries such as the Americans with Disabilities Act (ADA) in the United States or The Disability Discrimination Act (DDA) in the United Kingdom. Certain considerations must be made for wheelchair users, such as curb ramps and accessible pedestrian and crosswalk buttons. While people with disabilities are considered in urban planning practice, the evaluation tools of walkability offer only limited coverage of sidewalks for people with these different needs (Aghaabbasi et al., 2018).

\section{Social Capital and Social Equity}

Social sustainability is entwined with the concept of social capital, where social capital is leveraged for the provision of an organically operational social space that allows for the living, connecting, and bonding of humans (McKenzie, 2004; Yoo and Lee, 2016). Many constituent elements of social sustainability overlap with livability as we discussed earlier. The main distinction between the two concepts is the focused scope on subjective social interactions and behaviors by social sustainability with taking the historic and socioeconomic context more into account, while livability takes a wider area of objective and subjective factors and measures them to the instantaneous effect.

Social sustainability is manifested social equity and the sense of community despite disparities in income. Social equity requires accessibility to essential goods and services such as health, education, and recreation as well as enough economic equity 
for those services to be reasonably accessible to all. A socially sustainable neighborhood is characterized by a sense of unified community where common causes are identified and collective actions are taken or demanded from local authorities. Social sustainability and the value of social capital are often best reflected during crises such as natural disasters, pandemics, or economic hardships where individuals with better resources organize and intervene to help their communities. Social capital plays a role in mitigating the wider society and government's failure to provide vital functions such as security and welfare (Rayan, 2013).

\section{Creating a Social Space}

Walkability makes neighborhoods more sociable and fosters more frequent and longer interactions between members of a society, allowing for better bonding (Masoud et al., 2011). Nonetheless, an apparently weak or negative correlation between walkability and sociability can be a result of an amalgamation of cultural, socioeconomic, and ethnic contexts, which far exceeds the positive influence of the physical environment on societal relations. It is critical to understand that improvements neighborhood walkability and built environment cannot waive eons of racial and socioeconomic strain. The public discourse and major economic and social events have a stronger impact on social capital (Hanibuchi et al., 2012; Jun and Hur, 2015).

\section{Mobility}

Providing urban accessibility to broader range of individuals allows the inclusion of more people into productive social and economic activity and reduces the reliance on caretakers. Neighborhood walkability provides mobility to children or those who do not have cars. Mobility of children can free the time that parents normally dedicate to driving them to their sports activities. This freedom of mobility contributes to healthier, more sociable children and gives them access to community activities even in the event of parent's absence. This is a crucial issue to many parents who have to be committed to work schedules that conflict with their children's essential activities such as going to school. This dilemma leaves parents with options that either sacrifice the children's schooling or forgo a portion of their income (McDonald and Aalborg, 2009; Giles-Corti et al., 2011; Christiansen et al., 2014; Lee et al., 2020).

\section{Economic Sustainability}

Walking is a cost-effective transportation mode, especially for short distances, where pedestrians save not only on the fuel costs, but also on wear and tear on their automobiles. Walking helps reducing dependence on cars, and dilutes the need to bulky, expensive parking spaces. The social benefit of walkability transpires later as socioeconomic benefits, by creating vibrant environment for social interactions, inclusive job markets, clean environment, and accessibility to goods and serves. Nonetheless, we keep this section to focus on the direct financial benefits of walkability associated with cost reductions on the public and consumers, the benefits for the efficient land mixed use on property values, and the reduced burden on healthcare sector associated with increasing the physical activity levels among the population.

The following points outline aspects through which walkability contributes directly and indirectly to the economic and financial stability of taxpayers and government.

\section{Public and Consumer Cost Savings}

By estimating and measuring the money savings at both the personal and community levels for when car travel is replaced by walking, it is possible to report economic benefit from walkability. Consumers save money directly by reducing expenditure on fuel, reducing car consumption and parking fees. For example, improved perceived walkability affected the affordability of healthy food for the residents of Springfield, Missouri (Calise et al., 2018). In 2000, the total United States expenditure on walkability amounted to only $\$ 4.6$ billion out of $\$ 128.5$ billion spent on roadways on all government levels. However, progressively increasing budgetary resources are being dedicated to the development of walking and cycling tracks in recent years to present walking as a viable, supplementary transportation mode (Handy and McCann, 2010). Developing pedestrian infrastructure is evidently cheap and does not require as much funding as roadways (Litman, 2017).

Public savings are generated by reducing vehicle travel, thus reducing maintenance operations on existing roads and reducing the need for new roadways. Public savings can then extend to the consumer through tax cuts, and increased economic activity in livable, walkable cities will be reflected in improved tax revenue to public authorities. The Improved consumer accessibility, community livability, and consumer transportation yield cost savings that is beneficial for local business ecosystems, and are imperative to the success of tourism and retail sectors (Gorrini and Bertini, 2018). The reduction in car usage that results from walking leads to fuel savings on both the national and consumer levels; it also prolongs the lifespan of vehicles, which in turn reduces embodied carbon emissions.

\section{Efficient Mixed Land Use}

Walkability contributes to reducing the area dedicated for car transportation and parking, creating compact, accessible economic activity, and job opportunities for local communities. The presence of restaurants, retails shops, and recreation ventures contributes to creating a sense of vibrancy and liveliness, thus making increasing the attractiveness of the area, hence increasing its monetary evaluation. The mix-land use and connectivity of walkability maximizes the value of properties and occupation rates (Cortright, 2009; Pivo and Fisher, 2011). Efficient mixed land use in urban spaces is essential to build resilient cities and provide accessibility to residents within a reasonable distance.

\section{Healthcare}

Healthier populations are more economically productive, contribute to a larger labor supply, stronger tax-revenue and hence stronger financial standing, and more resources can be directed to those who are in more need for medical care; therefore, public health of the population is an essential 


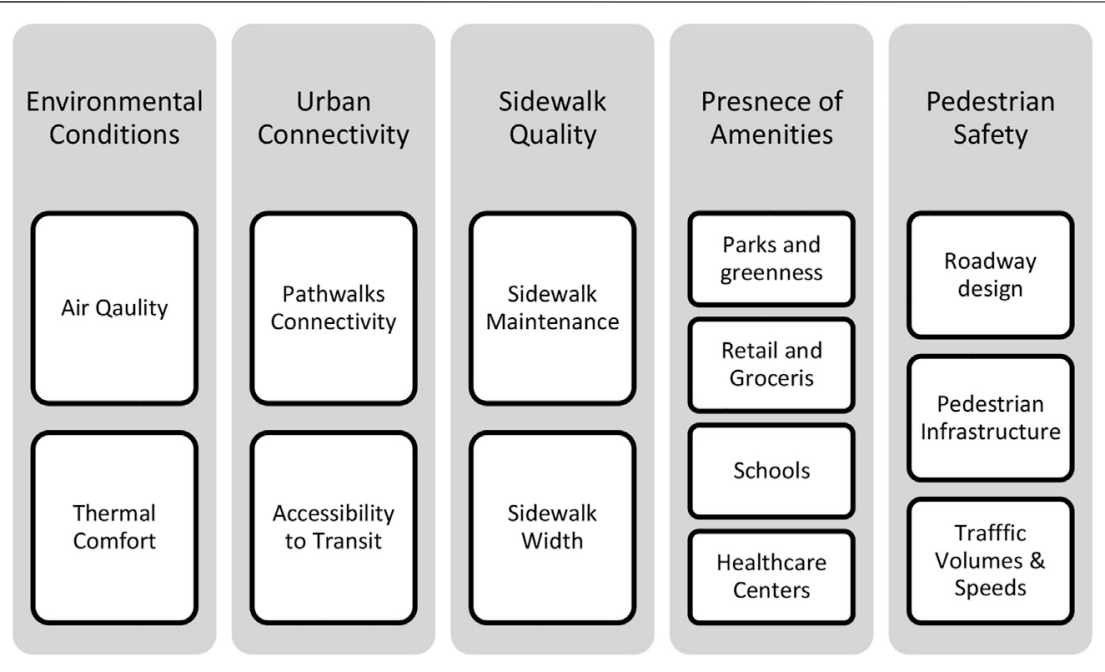

FIGURE 3 | Characteristics of walkable physical environment.

indicator to the economic performance. Increased physical activity by walking contributes to a healthier population and reduced mortality rates in older populations. Increased walking activity has been linked to reduced chronic diseases rates in healthier older women, older men, college students, and adolescents. Higher rates of physical activity are also associated with lower obesity rates as discussed in Walking and Health (Suhrcke et al., 2006).

\section{PHYSICAL ELEMENTS OF THE BUILT ENVIRONMENT}

Built environment has a positive influence on walking activity whether for transportation, leisure, or exercise. Built environment design must consider different transportation modes including walking. Rather than focusing on vehicles only, the development of urban spaces must focus on improving walkability to make physical activity and walking safe, easy, enjoyable, and accessible. Increasing physical activity in general and walking is associated with significant health benefits. Some of the physical features of the walkable zone are shown in Figure 3 with a discussion of their significant aspects afterward in the rest of the article.

\section{Connective and Accessible Built Environment}

The built environment must provide several intersections between connectivity and different utilities and amenities. The ability to walk continuously to the destination is by far the most important aspect of walkability and defines the possibility of the walking trip. Therefore, to encourage walking and physical activity, the built environment must provide comfortable pedestrian sidewalks, vehicle speed limits, appropriate road crossings, and good lighting. The walking trips must not be too long, and paths to destinations must be relatively direct. One attribute of connectivity is the density of intersections within a specific area, making navigation and accessibility much more direct and navigable due to smaller blocks. Another measure is to calculate the ratio of the direct geospatial distance between any two amenities to the actual traveling distance, which indicates how efficient walking is (Handy et al., 2002).

Unbalanced growth and planning can strip local communities of walkable characteristics, where streets dedicated to car and parking spaces take priority, while width of sidewalks shrink and pedestrian movement therefore ends up concentrated in only a small number of street segments that are exposed to encroachment and obstacles. This leads to the creation of vibrant pockets where walking is beneficial, safe, and comfortable while the rest of the city is barred from urban vibrancy and liveliness (Zook et al., 2012).

\section{Mix Land Use}

Another factor that encourages walkability is having mixed land use of the built environment. Multiple applications of the developed urban area ensure the activity of the residents and visitors since walking becomes an accessible utilitarian tool to transport between residential, recreational, entertainment, and retail services, as well as institutions such as schools, offices, community centers, and houses of worship. Such facilities being in close proximity in compact communities lead to individuals walking up to two and half times more than those who live in sparse communities. This is due to the ability to use walking as an efficient and quick mode to reach destinations of daily utility (Coogan et al., 2007). Planned walkways must, then, be direct and efficient to minimize unnecessary traveling in utilitarian walks. Walkability increased the valuation of built real-estate assets between 1 and $9 \%$ of the property value in the United States (Pivo and Fisher, 2011). Land prices are also influenced by walkability, as pointed out by Rauterkus and Miller (2011) who studied land prices in Alabama. 


\section{Greenness and Parks}

A significant feature of the built environment is outdoor greenness. In addition to being aesthetically appealing, vegetation and trees reduce temperatures, spread shadows, and improve air quality. A pleasant experience is walking through a park during the commute to work, and increasing the greenness around the workplace increased the overall physical activities of adults (Marquet et al., 2020), and having a cleaner air which encourages walking (James et al., 2017). Most frameworks use greenness and parks in their assessments of walkability, as will be discussed in greater detail in Evaluation and Measurements of Walkability (Dills et al., 2012).

\section{Transit Hubs and Transit-Oriented Development}

The objective of Transit-Oriented Development (TOD) is to encourage the use of public transport by placing the residential and commercial areas within a walking distance from public transportation points. A positive effect of TOD is the reduction of car ownership and usage, which in turn reduces the carbon footprint of urban centers as well as traffic congestion, and by saving spaces usually allocated for parking, more land becomes accessible for housing, parks and green spaces, and economic activities. Walkability is a core element of TOD since walking is the main mode of transportation to travel short distances between the destinations and the transportation station or hub. Connective, direct, and comfortable walking are major factors necessary to improve access to transit. Through microlevels of improvement in walking infrastructures, the effective radius of walkability can be further improved and extended (Park et al., 2015). TOD revolves around the availability of inexpensive and reliable public transportation such as metro subways and public buses that allow pedestrians to reach to public transportations stations by walking and then commuting to and from work. Studies such as Jeffrey et al. (2019) have found that train stations located in older, more walkable, and dense areas are more heavily used than train stations in developing areas with less walkability and less population.

The use of public transportation contributes to the reductions of greenhouse emissions and traffic congestion; however, many pedestrians using the transit services have to move through unwalkable conditions between their destination and the transit station, and cannot possibly make a continuous walking trip to endangering their health and safety (Shaheen and Chan, 2016; Chidambara, 2019). Discontent of residents might surface when the developers and governments neglect designing safe, connective, walkable infrastructure for pedestrians, and prioritize designing the infrastructure to address the increasing number of automobiles and congested traffic to levels that encroach on open public spaces and suffocate access to transit stations (Noland et al., 2017; Lamour et al., 2019). Ironically, diminishing the walkability around transit hubs and limiting access to public transportation in the pursuit of solving traffic congestion will ultimately force residents onto more dependency on private vehicles, thus aggravating the problem of traffic congestion even more.

\section{Pedestrian Thermal Safety and Comfort}

Thermal comfort is a significant factor in influencing pedestrians' decision to walk. Increasing temperatures due to global warming as well as the excess heat generated by urban centers, known as urban heat islands, add to the challenges of walkability and pedestrian safety. Long-term health benefits of outdoor physical activity might be offset by unpleasant weather conditions and extreme thermal discomfort in addition to thermal health risks such as hypothermia and frostbite in cold weather and sun stroke and heat exhaustion in hot weather (Donny Koerniawan, 2014; Ebrahimabadi et al., 2015; Rakha, 2015; Yao et al., 2018). Thermal discomfort leads to unintended consequences in transportation patterns. The decline in walking and cycling is met with an increased adoption and use of private automobiles and, in some cases, public transportation. Public transportation that depends on walking or biking to transit stations will face a challenge and private cars will often be relied on more heavily (Shaaban et al., 2017; Silva and Akleh, 2018). Nonetheless, in most walkability frameworks, thermal safety is given much lower priority than connectivity or features of the built environment. Even an index such as Walk Score does not give any considerations to thermal factors.

Thermal comfort is subjective and differs between individuals but only within boundaries of human physiology. The main concept behind thermal comfort is thermal equilibrium between the human body and the surrounding environment. Different evaluation methods of thermal comforts aim at correlating individual's thermal sensations with measured thermal parameters such as temperature, humidity, and wind speed. The physiological condition of the individual also plays a part, where their level of physical activity, age, and health status might yield differences in perceived thermal comfort. Recent case studies point out that thermal sensation exists on three levels: physical, physiological, and psychological. Sensation of the temperature is heavily influenced by psychological factors even when physical parameters and physiological parameters are controlled. Some methods to measure thermal comforts are Universal Thermal Climate Index (UTCI), Predicted Mean Vote (PMV), Physiological Equivalent Temperature (PET), and Standard Effective Temperature (SET) (Nikolopoulou and Steemers, 2003; Elnabawi and Hamza, 2020).

Thermal comfort remains an unsolved challenge in urban planning. Weather challenges are globally diverse in terms of temperature, humidity, and wind speed, and mitigation efforts differ greatly. In addition to organizational and policy challenges, urban planners struggle to find tools for estimating extreme conditions such as snow accumulation, rain, and sandstorms in both cold and hot climates (Atef Elhamy Kamel, 2013; Ebrahimabadi et al., 2015; Rahman and Nahiduzzaman, 2019). Thermal discomfort is seasonal and temporal in nature; in hot climates, walkable distance correlates with the particular season and the time of day, with people being able to walk significantly less during the afternoon and significantly more at night. This is flipped in cold climates, where walkability increases during the daytime and decreases during the colder night. Walking during the summer in hot climates or the winter in cold climates can be a risky endeavor since even thermal comfort mitigation solutions 
cannot compensate for extreme differences in temperature (Chapman et al., 2017; Shaaban et al., 2017; Shaaban et al., 2018).

Understanding of the effect of the built environment and how this is translated onto thermal stress levels with the pedestrians is still limited. Thermal measurements are often taken by weather stations but do not accurately represent the thermal experience of the pedestrian, and how it is affected by shade, sunlight greenery, and the thermal mass of the surrounding environment. Several recent works attempt to measure the thermal comfort of the microclimate in which pedestrians are present, using wearable sensors (Nakayoshi et al., 2014; Chokhachian et al., 2018; Mamun and Yuce, 2019; Pigliautile et al., 2021). Another approach would be the use of thermal imaging using drone technology, which in this case would be capable of measuring the thermal conditions of surfaces within the range of the infrared thermography, as well as temperature and humidity using the sensors embedded on the drone (Fabbri and Costanzo, 2020).

Strategies to mitigate thermal discomfort and improve thermal safety differ by the type of climate. In the phases of urban design, design of street orientation for thermal comfort is possible by engineering the orientation of streets to have the maximum shade in hot hours (Sharmin and Steemers, 2013; Silva, 2017; Rodríguez-Algeciras et al., 2018). In hot climates, shading, vegetation, and white surfaces are some strategies that have been found to increase thermal comfort and the specific use of evaporative techniques in arid hot climates (Taleghani, 2018).

\section{Pedestrian Road Safety}

The perception of road safety influences the levels of walking and cycling in the community, particularly among the elderly and children. The presence of appropriate well-designed walking and crossing facilities can encourage pedestrians to walk (Sisiopiku and Akin, 2003; Timperio et al., 2004; Giles-Corti et al., 2011)

Pedestrian safety in the context of built environment, as per a top down conceptual top-down framework introduced by Siqueira et al. (2021), is determined on three scales, first in the development scale: density, urban sprawl and expansion, and regional development describes the development patterns and urban planning requirements. Secondly on the local scale: the roadway design and pedestrian infrastructure, including signs and crossing markings. Thirdly, on the street scale, with factors such as the traffic volumes and traffic speeds. These interact with factors such as the driver's behaviors, the demographic breakdown of pedestrians primarily, age, and the physical abilities, and potential distractions on the road such as the use of smart phones.

Factors that control and mitigate the pedestrian accidents include the need to cross traffic intersections. Wider roads, higher number of lanes, and higher speed limits are associated with higher accident rates and less feeling of safety (Gårder, 2004).

\section{EVALUATION AND MEASUREMENTS OF WALKABILITY}

There is no single universal measure that can capture all the significant factors of walkability due to the variety of built environments, cultures, and climates. Measuring walkability can be done via analysis of the surrounding of the attributes of the built environment and aggregated into a singular walkability index or score. There are several software programs, code libraries, and commercial services that investigate the walkability of a neighborhood. One subjective measurement of walkability is surveys; self-reported activities are also common and used to capture the feelings and behaviors of pedestrians and help highlight aspects that cannot be captured by objective technical analysis.

Walkability measures are generally classified into three categories: objective measures, subjective measures, and distinctive measures (Maghelal and Capp, 2011). These types are explained in Figure 4.

\section{Measuring Walkability Through Objective Indices}

Objective indices of walkability evaluate the presence of desirable features in the studied area. These features include greenness, access to public transportation, and the presence of amenities. Whether commuting for work or non-work purposes, objective walkability indices are indicators of the quality of the ease and comfort of walking in a neighborhood via scientifically measurable parameters. Below are some of these parameters, most of which are based on geospatial information systems (GIS):

\section{- Land Use Diversity Index (LDI)}

The land diversity index (LUDI) Yoshida and Tanaka (2005) measures the diversity use purposes of the land. It is relevant because it measures how easily residents can enjoy different necessary amenities and services in a close vicinity with limited use of car transportation, which improves livability (Litman, 2017). Mix land use also has been correlated to higher rates of walking and lower body BMI (Brown et al., 2009). The land use index is useful for measuring walkability and usefulness of public transport. There are many approaches to formulate LUDI, such as Danielle Comer a, J. Scott Greene or Yoshida and Tanaka (2005). One interpretation of the Shannon entropy formula by Manaugh and Kreider (2013) takes into account the following: the ratio of the area of land-use type over the total area of the study zone, and the number of different land-uses within study zone.

For this index, the constituent parameters can be selected according to the local context of the studied area, for example mix land use may include or exclude certain types of residential buildings or dormitories, commercial spaces such as grocery stores, restaurants and/or coffee shops, institutional spaces such as schools or police stations, entertainment hubs such as cinemas, and recreational spaces such as gyms or parks.

\section{- Intersection Density Index (IDI)}

Intersection density index (IDI) is simple to calculate, by simply counting the number of street intersections in a defined area. Higher intersection density means that reaching 


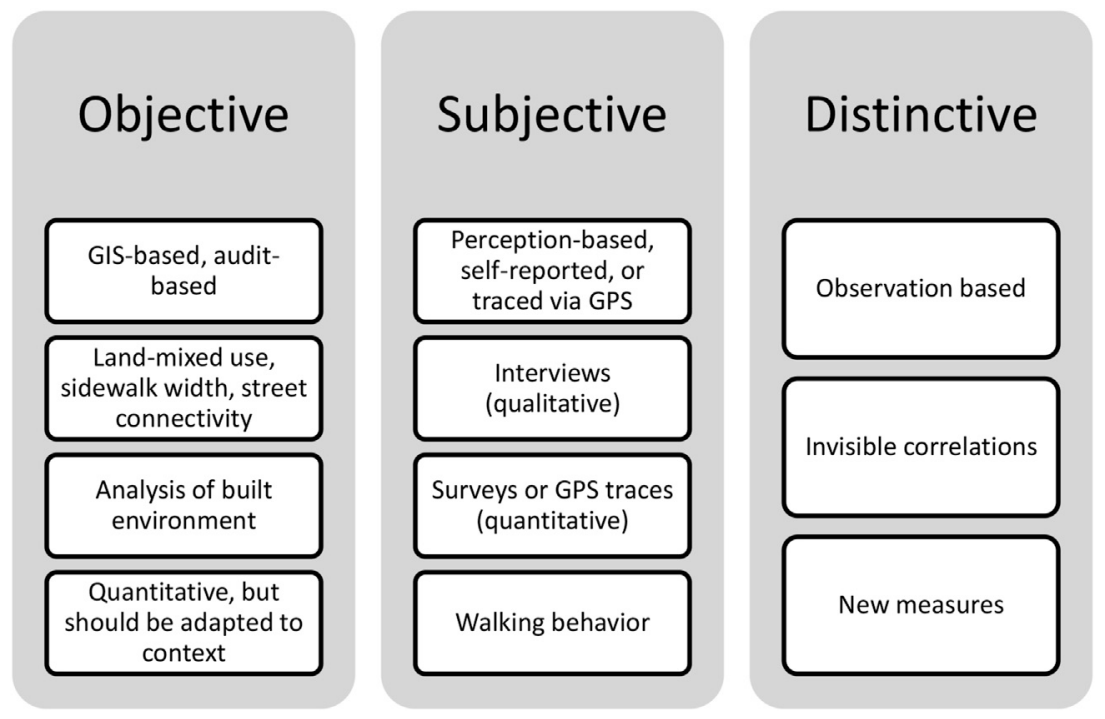

FIGURE 4 | Walkability measures types. Modified from Maghelal and Capp (2011).

a destination is relatively easy and direct (Shashank and Schuurman, 2019). IDI is indirectly correlated to block length, which, as mentioned above, is one of the major inputs used to calculate in walkability indicators such as WalkScore.

- Public Transportation Accessibility Index (PTAI)

The public accessibility transport index (PTAI) measures the connectivity of buses, trams, and subway metros. The connectivity offered by public transport extends the effective traveling range of users without a private car, contributes to lower $\mathrm{CO}_{2}$ emissions, and reduces stress on transportation resources. Higher PTAI indicates the ability of the population to avoid using private cars when accessing local recreational and entertainment facilities that are traditionally too far away to be reached by walking. This encourages walking to the public transport. Higher PTAI score indicates the mitigation of long average distance or time and is a strong indication of good implementation of TOD principles. The PTAI can be calculated using GIS such as Network Analyst (Brown et al., 2009; McCormack et al., 2012).

\section{- Pedestrian Route Directness Index (PRD)}

PRD aggregated over all amenities and destinations. Being closer the number to 1 indicates higher efficiency of walking. Higher street intersections usually indicate a good walking connectivity as shortcuts to the efficient routes are more prevalent. The PRD can be calculated by simply diving the length of the walking routes over the geodesical distance between the origin point and the destination (Stangl, 2012).

- Population Density Index (PDI)

The population density index (PDI) measures the number of populations living or commuting in an area. PDI correlates positively with a sense of community and safety from crime. In addition, higher population density attracts commercial, entertainment, and recreational amenities. Therefore, the average walking time is usually shorter due to the abundance of destinations within a small proximity (Duncan et al., 2013).

\section{- Normalized Difference Vegetation Index (NDVI)}

Normalized Difference Vegetation Index (NDVI) is an image processing-based index that measures the vegetation of an area from satellite red and infrared images integrated with GIS data, and was introduced by Tucker (1979). It is an index used widely in literature and can measure the effect of not only parks and greenspaces but also street vegetation that provides shade and aesthetic comfort. The NDVI of an image is calculated from distinguishing the red and near infra-red color bands of an image. Cooler image temperatures usually indicate denser greenery (Samarasekara et al., 2011).

\section{Subjective Walkability Evaluation}

Diverging from the quantified objective GIS-based indices mentioned in the previous section, subjective walkability evaluations are done through surveys, focus group discussions, interviews, and audits. Subjective evaluations, especially interviews, offer insights into zone-specific context and help assign priorities in walkability frameworks and responses differ based on socioeconomic conditions, demographics, and local culture. Understanding the social dimension of walkability requires the engagement with the individuals of the neighborhood and the nature of social connections (van den Berg et al., 2017).

The most common subjective tools are surveys, since they are capable of covering larger samples, and they measure the pedestrian satisfaction levels in certain regions. Other methods include focus group discussions, which allow for in-depth insights 
especially for specific demographic lines, such as gender (Golan et al., 2019), or a specific aspect such as pedestrian safety (Villaveces et al., 2012). Subjective evaluations are particularly useful in revealing the pedestrian priorities and identifying the barriers to walking, for example subjective evaluations from hot climates highlight the importance of thermal comfort, while this factor receives less emphasis in the much cooler developed countries. Subjective walkability evaluations are effective tools to investigate pedestrian satisfaction and experience and nudge the research and analysis into effective directions (Atef Elhamy Kamel, 2013; Mohamed et al., 2016). Furthermore, subjective evaluations can identify efficient solutions for walkability issues by individuals with intimate knowledge with the investigated site, for example, a survey conducted by Azzali and Sabour (2018) found that the student and staff of Qatar University suggested improving campus walkability was simply to increase shading in their pathways from the parking to the lecture halls. This suggestion succeeded in identifying the sun radiation as the prominent factor in making that environment unwalkable and dispel with the assumption stating that environment cannot become walkable due to the high temperatures. Such surveys can act as priors to guide more detailed objective analyses, or even become the evidence driving policy action when faced with time constraints. Most subjective evaluations focus on people's perceptions, and by contrasting the results with objective measurements, it is possible to compare the results to reach estimations of an optimal environment (Lin and Moudon, 2010).

Pedestrian perceptions of surrounding amenities are correlated through walkability frameworks such as the Walkable and Bikeable Community (WBC) project (Lin and Moudon, 2010), which measures the perceptions of pedestrians through simple yes-or-no questions that are then compared with objective measures from the same zones. The participant's perception of the destinations at which they frequent, and their actual number will be studied, as well as the perception of the presence of shops and their actual level of accessibility. The perceived opportunities to exercise recreational physical activity whether indoors or outdoors can be contrasted with the number, size, and quality of the existing facilities; perceptions of traffic will be contrasted with the actual traffic volume and speed; perceptions of footpaths for walking will be compared to an audit of the size, width, connectivity and quality of footpaths; opinions on the aesthetics factors of the surrounding environment will also be discussed alongside quantification.

New factors have been introduced recently, such as sky view factor. It indicates the portion of the sky that is visible. It is an open space factor, which correlates to the ratio of parks to other land as well as air temperature and thermal comfort (Donny Koerniawan, 2014). According to subjective evaluations done in GCC countries, comparative analysis of three different walkability indices in Canadian districts showed a variation in walkability results. In addition, most studies give a walkability result for the entire year without consideration to variation in weather that occurs throughout the year (Shashank and Schuurman, 2019).

New evaluation methods have even emerged from advancements in image processing and computer vision. By processing and evaluating pictures and satellite images as well as traffic information of studied zones, Yencha (2019) analyzed 60,000 house transactions in Ohio, United States using panorama images. The results found that the property value increased with accessibility to sidewalks and comfortable footpaths as well as other walkability-related built environment factors such as street lighting. Computer vision in this case is successful in indicating socioeconomic development challenges in certain neighborhoods. Other works are dedicated to translating opinion-based subjective measures to predictable objective measures using neural networks (Sabzali Yameqani and Alesheikh, 2019).

\section{Frameworks to Evaluate Walkability}

Several walkability frameworks are well established already, and some are used by national urban development agencies. Specific features of the built environment are evaluated. For example, researchers have studied the aesthetic cues of the environment, sidewalks, and comfort levels. An effective methodology is street segmentation, which consists of analyzing every segment for its pavement quality, accessibility, and connectivity. In the following, a few frequently used walkability evaluation frameworks.

\section{Pedestrian Environment Review System}

This is an auditing tool for pedestrian walkability evaluations. The PERS tool is based on objective assessments of on-street images and GIS-based data. This tool is widely used by urban planning agencies in the United Kingdom. PERS is developed to assess walkability in the presence of links, bridges, public spaces such as parks, and public transport. PERS software, sold by the TRL Group, gives a special emphasis to walkability to public transportation modes and interchanges since a large segment of the population uses public transportation to commute to work. Each node, representing a building or a significant point, is rated according to connectivity on a point system.

\section{C Framework}

This framework defines five essential attributes of the built environment required for walkability. It is built on five " $\mathrm{C}$ " following attributes:

1) Convenient: Open urban spaces such as walkways, parks, and other venues for physical activity must be close to the locations of pedestrian's constant presence such as their residential areas or work spots. Walking in this case must be a viable alternative in terms of time, money, and effort.

2) Connected: Urban open spaces should be consistent with sustainable design principles, protect the environment, and maximize social connectivity.

3) Conspicuous: This is the concept that urban open spaces must be clearly designated and protected from traffic, encroachment, and must be regularly maintained and cleaned.

4) Convivial: Convivial urban design focuses on making spaces pleasant and enjoyable for pedestrians. The urban space should be designed to create a sense of community.

5) Comfortable: Comfortable walking should consider safe, spacious, walkways that are protected from harsh weather, 
excessive sunlight, and speeding traffic noise and emission as well as prioritize providing opportunities for rest and shelter.

\section{C Framework}

Building on the previous five factors, Moura et al. (2017) have proposed two additional attributes. They are as follows:

6) Coexistence: This is the presence of different transportation modes within the same area that allow the pedestrians to fill their own diverse needs. In addition, this factor evaluates the negative dominance of automobile traffic, which is one of the major safety concerns with pedestrians and gives them a sense of inferiority (Koh and Wong, 2013). This feeling can be exacerbated in the GCC with the dominance of large SUV automobiles. The safety of pedestrians is severely compromised by careless drivers who often engage in dangerous activities such as talking on the phone while driving. Crossing the street from driver's blind spots also poses a safety concern for pedestrians (Suarez-Balcazar et al., 2020).

7) Commitment: This refers to the commitment of local authorities and agencies to support a walkable, healthy environment.

\section{Pedestrian Environment Data Scan}

The PEDS tool analyzes 78 measures that describe the built environment and the pedestrian footpath quality of street segments. PEDS is carefully designed to change the weight of the attributes according to the purpose of the walk whether it is to transit stations, walk to work, or walk for pleasure. The analysis includes the land mix use attributes and the greenness factors.

\section{Neighborhood Environment Walkability Scale}

NEWS focuses on parameters describing the livability in a Neighborhood. NEWS is based on self-reporting by the participants in surveys in regard to safety from crime, aesthetics, traffic, and environment (Zuniga-Teran et al., 2017). The major factors evaluated in NEWS are residential density, accessibility to non-residential land uses, street connectivity, places for walking and cycling, neighborhood surroundings, safety, and satisfaction.

\section{The Walking Suitability Index of the Territory}

This is a composite index introduced by Appolloni et al. (2019). TWSI consists of major categories: practicability, safety, urbanity, and appeal. The Practically category measures the Sidewalk surface obstacles, and slope. Safety measures safeguard from vehicles, road lighting, and facilitate safe crossing. Urbanity, which is defined by the quality of urban life, measures the hospitability of the sidewalk to pedestrians. The major indicators are sidewalk width, availability of street furniture such as benches and shade, or a mixture of activities denoted by an activity mix indicator. The fourth category, appeal, measures traffic's ability to disturb walking by noise from high speeds and building stock, which denotes the visual appeal of the surrounding buildings. The final and most important indicator, vegetation, measures the greenness of the planted strips on sidewalks and the surrounding environment.

\section{Commercial Walkability Measure: Walk Score}

Walk Score is an aggregate index provided by the private company Walk Score and is used to evaluate walkability in urban areas via a singular evaluation number of 100 . Walk Score aims at being a factor in real estate pricing. Multiple researchers have analyzed housing prices in the United States and their correlation with the Walk Score indicator.

The methodology used to calculate Walk Score (Cohen and Davies, 1995) is based on two independent categories of evaluation. The first is the presence of amenities such as restaurants, grocery stores, shopping, schools, and parks where each of amenities is assigned a weight factor. The other category is pedestrian friendliness, which is evaluated using two indicators: the intersection density, measured by the number of intersections per square mile, and average block length. A highly walkable neighborhood has a high density of diverse amenities, high intersection density, and short average block length. Walk Score aims to use the index as a tool to influence housing prices, as walkability is not only a cursor of sustainability but also livability. Cortright (2009) analyzed the property prices in 15 United States cities, and found that on average walkability corresponds to higher property value. Furthermore, Pivo and Fisher (Pivo and Fisher, 2011) found that houses in walkable neighbourhood were characterized with lower caps rates and higher incomes, indicating that walkable neighborhoods have a favorable position in real estate and investment markets. However, there might be other factors that affect the influence of walkability on housing prices. Outside the United States, Zhang et al. found that walkability is negatively correlated to real estate value in Futian District, China (Zhang et al., 2019). This is due to factors related to the economic activities in the region and is unrelated to walkability. Similarly, there is no correlation as in the case of Seoul, Korea (Kim and Kim, 2020).

While it is a valuable tool to quickly evaluate a walkability scene, Walk Score does not consider other critical factors in inspiring the decision to walk such as greenness (Marquet et al., 2020), air quality (Howell et al., 2019), pavement quality, or thermal comfort (Atef Elhamy Kamel, 2013).

\section{CONCLUSION}

The conceptual correlations, and to a lesser extent practical correlation, between walkability from one side, sustainability, livability, and health from the other have been well defined in recent literature; walkability has been shown to be a reconciling solution that can serve long-term sustainability, short-term livability goals, and health of individuals. Improving walkability not only contributes to more efficient use of energy but also adds vibrancy by improving resident, tourist, and visitor access. 
With more than one billion people suffering from some form of mobility challenge according to the World Health Organization (WHO), future walkability endeavors will aim to make the conditions of the built environment more inclusive. Nonetheless, tools and methods analyzing accessibility and walkability for the disadvantaged and disabled leave more to be desired, as they rarely consider the details that harshly influence the access and connectivity of people with wheelchairs. Economically disadvantaged communities rely on walking as a cost-free mode of transportation. Improving the walking infrastructure improves their access to services and job opportunities, which in turn promotes better social health and social capital. While the correlation between walkability and sociability is not necessarily linear as shown in data from short-term studies, we hypothesize that increasing the interactions between different classes of society will help improve social mobility and remove ethno-racial sensitivities in the long term. This has yet to be proven academically and should be the subject of further studies.

The health benefits of walking and outdoor exercises will likely be more heavily promoted in the aftermath of the COVID-19 pandemic. Walkability and physical activity in general are associated with better health conditions and the reduction of non-chronic diseases. Older populations with health issues and those with pre-existing conditions were more susceptible to death from COVID-19. Walking outdoors and exposure to the sun is correlated to vitamin $\mathrm{D}$ deficiency, which affects the immune system (Van den Heuvel et al., 2013; Grant et al., 2020; McCartney and Byrne, 2020).

With the near ubiquity of GPS-equipped smartphones, more research can be done to investigate the actual walking behavior and movement patterns of pedestrians (Marra et al., 2019; Yamagata et al., 2019; Mooney et al., 2020). GPS apps can be used by pedestrians to identify and flag issues seen on the streets that affect their access and walkability, creating a real-time feedback mechanism that mitigates errors and omissions from memories and identifies the unstructured routes and shortcuts actually taken by pedestrians (Lue and Miller, 2019).

Thermal stress/comfort and air quality are major challenges to the walking experience, but they are poorly quantified in current evaluation and audits due to the lack of sufficient data. Thermal sensation is only implicitly expressed within the presence of vegetation or shading or lumped under the comfort indices, while this is reasonable in moderate climates where many of the studies are conducted. Nonetheless, thermal

\section{REFERENCES}

Aghaabbasi, M., Moeinaddini, M., Zaly Shah, M., Asadi-Shekari, Z., and Arjomand Kermani, M. (2018). Evaluating the Capability of Walkability Audit Tools for Assessing Sidewalks. Sustainable Cities Soc. 37, 475-484. doi:10.1016/j.scs.2017.12.001

Appolloni, L., Corazza, M. V., and D'Alessandro, D. (2019). The Pleasure of Walking: An Innovative Methodology to Assess Appropriate Walkable Performance in Urban Areas to Support Transport Planning. Sustainability 11, 3467. doi:10.3390/su11123467

Atef Elhamy Kamel, M. (2013). Encouraging Walkability in GCC Cities: Smart Urban Solutions. Smart and Sust Built Env 2, 288-310. doi:10.1108/SASBE-032013-0015 stress in hot climates becomes an issue of safety that stymie most outdoor activities, including walking, or/and easily negates any positive features of the built environment. Similarly, air pollution nullifies the health benefits from walking outdoors, and induces a slew of respiratory and cardiovascular diseases. To understand how both issues influence pedestrians, recent studies opted to collect microclimate environmental measurements during the walking experience using wearable and portable suites of sensors. This pedestrian-centered approach is still in its infancy and has a room for development in improving the measurements hardware, covering more diverse microclimates, simulating the pedestrian experience of a more diverse demographics, or/ and measuring the difficulty of purpose-defined trips such as trips to transit stations.

There is a need for a framework of walkability that emphasizes thermal safety and air quality, especially with respect to different demographics and activities. Walkability frameworks need to be more sensitive to the microclimate and thermal comfort factors, which greatly influence the pedestrian's decision to walk. One reason is that weather and climate measurements are traditionally taken on the district level, and data understanding of the microclimate and how it is influenced by the built environment, and how it is exposed to the pedestrians.

\section{AUTHOR CONTRIBUTIONS}

$\mathrm{AB}$ and SA-G: conceptualization and methodology. AB: writing-original draft. SA-G and MK: writing-review and editing. SA-G: supervision and funding acquisition. All authors have read and agreed to the published version of the manuscript.

\section{ACKNOWLEDGMENTS}

This research was supported by a scholarship from Hamad Bin Khalifa University (HBKU), a member of Qatar Foundation (QF). Any opinions, findings, and conclusions or recommendations expressed in this material are those of the author(s) and do not necessarily reflect the views of the HBKU or QF. Open Access funding provided by the Qatar National Library.

Azzali, S., and Sabour, E. A. (2018). A Framework for Improving Sustainable Mobility in Higher Education Campuses: The Case Study of Qatar University. Case Stud. Transport Pol. 6, 603-612. doi:10.1016/j.cstp.2018.07.010

Barton, J., Hine, R., and Pretty, J. (2009). The Health Benefits of Walking in Greenspaces of High Natural and Heritage Value. J. Integr. Environ. Sci. 6, 261-278. doi:10.1080/19438150903378425

Brown, B. B., Yamada, I., Smith, K. R., Zick, C. D., Kowaleski-Jones, L., and Fan, J. X. (2009). Mixed Land Use and Walkability: Variations in Land Use Measures and Relationships with BMI, Overweight, and Obesity. Health \& Place 15, 1130-1141. doi:10.1016/j.healthplace.2009.06.008

Calise, T. V., Chow, W., Ryder, A., and Wingerter, C. (2018). Food Access and its Relationship to Perceived Walkability, Safety, and Social Cohesion. Health Promot. Pract. 20, 858-867. doi:10.1177/1524839918778553 
Chapman, D., Nilsson, K., Larsson, A., and Rizzo, A. (2017). Climatic Barriers to Soft-Mobility in winter: Luleå, Sweden as Case Study. Sustainable Cities Soc. 35, 574-580. doi:10.1016/j.scs.2017.09.003

Chazal, J. d. (2010). A Systems Approach to Livability and Sustainability: Defining Terms and Mapping Relationships to Link Desires with Ecological Opportunities and Constraints. Syst. Res. 27, 585-597. doi:10.1002/sres.1058

Chidambara (2019). Walking the First/last Mile To/from Transit: Placemaking a Key Determinant. Up 4, 183-195. doi:10.17645/up.v4i2.2017 https://spa.irins. org/profile/97362, https://www.cogitatiopress.com/urbanplanning/article/ view/2017, https://www.scopus.com/authid/detail.uri?authorId=57191828887.

Chiu, H.-Y., Huang, H.-C., Chen, P.-Y., Hou, W.-H., and Tsai, P.-S. (2015). Walking Improves Sleep in Individuals with Cancer: A Meta-Analysis of Randomized, Controlled Trials. Onf 42, E54-E62. doi:10.1188/15.ONF.E54-E62

Chokhachian, A., Ka-Lun Lau, K., Perini, K., and Auer, T. (2018). Sensing Transient Outdoor comfort: A Georeferenced Method to Monitor and Map Microclimate. J. Building Eng. 20, 94-104. doi:10.1016/j.jobe.2018.07.003

Christiansen, L. B., Toftager, M., Schipperijn, J., Ersbøll, A. K., Giles-Corti, B., and Troelsen, J. (2014). School Site Walkability and Active School Transport Association, Mediation and Moderation. J. Transport Geogr. 34, 7-15. doi:10.1016/j.jtrangeo.2013.10.012

Cohen, M., and Davies, J. K. (1995). Spectral Irradiance Calibration in the Infrared - V. The Role of UKIRT and the CGS3 Spectrometer. Mon. Not. R. Astron. Soc. 276, 715-722. doi:10.1093/mnras/276.3.715

Comer, D., and Greene, J. S. (2015). The Development and Application of a Land Use Diversity index for Oklahoma City, OK. Appl. Geogr. 60, 46-57. doi:10.1016/j.apgeog.2015.02.015

Coogan, M. A., Karash, K. H., Adler, T., and Sallis, J. (2007). The Role of Personal Values, Urban Form, and Auto Availability in the Analysis of Walking for Transportation. Am. J. Health Promot. 21, 363-370. doi:10.4278/0890-1171-21.4s.363

Cortright, J. (2009). Walking the Walk: How Walkability Raises home Values in US Cities. Durham, NC: CEOs for Cities.

Cowen, C., Louderback, E. R, and RoySen, S. S. (2019). The Role of Land Use and Walkability in Predicting Crime Patterns: A Spatiotemporal Analysis of Miami-Dade County Neighborhoods, 2007-2015. Secur. J. 32, 264-286. doi:10.1057/s41284-018-00161-7

Dills, J. E., Rutt, C. D., and Mumford, K. G. (2012). Objectively Measuring RouteTo-Park Walkability in Atlanta, Georgia. Environ. Behav. 44, 841-860. doi:10.1177/0013916511404409

Donny Koerniawan, M. (2014). Thermal Comfort and Walkability in Open Spaces of Mega Kuningan Superblock in Jakarta Liveable and Walkable City View Project Building Performance Simulation for Hot-Humid Climate View Project. doi:10.13140/2.1.4388.5766

Duncan, D. T., Aldstadt, J., Whalen, J., and Melly, S. J. (2013). Validation of Walk Scores and Transit Scores for Estimating Neighborhood Walkability and Transit Availability: a Small-Area Analysis. GeoJournal 78, 407-416. doi:10.1007/s10708-011-9444-4

Ebrahimabadi, S., Nilsson, K. L., and Johansson, C. (2015). The Problems of Addressing Microclimate Factors in Urban Planning of the Subarctic Regions. Environ. Plann. B Plann. Des. 42, 415-430. doi:10.1068/b130117p

Elnabawi, M. H., and Hamza, N. (2020). Behavioural Perspectives of Outdoor Thermal Comfort in Urban Areas: A Critical Review. Atmosphere (Basel). 11, 51. doi:10.3390/atmos11010051

Fabbri, K., and Costanzo, V. (2020). Drone-assisted Infrared Thermography for Calibration of Outdoor Microclimate Simulation Models. Sustainable Cities Soc. 52, 101855. doi:10.1016/j.scs.2019.101855

Forsyth, A. (2015). What Is a Walkable Place? the Walkability Debate in Urban Design. Urban Des. Int. 20, 274-292. doi:10.1057/udi.2015.22

Frackelton, A., Grossman, A., Palinginis, E., Castrillon, F., Elango, V., and Guensler, R. (2013). Measuring Walkability: Development of an Automated Sidewalk Quality Assessment Tool. SubSust 1, 4. doi:10.5038/2164-0866.1.1.4

Frank, L. D., and Engelke, P. O. (2001). The Built Environment and Human Activity Patterns: Exploring the Impacts of Urban Form on Public Health. J. Plann. Lit. 16, 202-218. doi:10.1177/08854120122093339

Gårder, P. E. (2004). The Impact of Speed and Other Variables on Pedestrian Safety in Maine. Accid. Anal. Prev. 36, 533-542. doi:10.1016/S0001-4575(03)00059-9

Giles-Corti, B., Wood, G., Pikora, T., Learnihan, V., Bulsara, M., Van Niel, K., et al. (2011). School Site and the Potential to Walk to School: The Impact of Street Connectivity and Traffic Exposure in School Neighborhoods. Health \& Place 17, 545-550. doi:10.1016/j.healthplace.2010.12.011
Glaeser, E. L., and Kahn, M. E. (2004). "Sprawl and Urban Growth," in Handbook of Regional and Urban Economics (Elsevier), 2481-2527. doi:10.1016/s1574-0080(04)80013-0

Golan, Y., Henderson, J., Wilkinson, N. L., and Weverka, A. (2019). Gendered Walkability. J. Transp. Land Use 12, 501-526. doi:10.5198/jtlu.2019.1472

Gorrini, A., and Bertini, V. (2018). Walkability Assessment and Tourism Cities: the Case of Venice. Int. J. Tour. Cities. doi:10.1108/ijtc-11-2017-0072

Gough, M. Z. (2015). Reconciling Livability and Sustainability. J. Plann. Education Res. 35, 145-160. doi:10.1177/0739456X15570320

Grant, W., Lahore, H., McDonnell, S., Baggerly, C., French, C., Aliano, J., et al. (2020). Evidence that Vitamin D Supplementation Could Reduce Risk of Influenza and COVID-19 Infections and Deaths. Nutrients 12, 988. doi:10.3390/nu12040988

Gregg, E. W., Gerzoff, R. B., Caspersen, C. J., Williamson, D. F., and Narayan, K. M. V. (2003). Relationship of Walking to Mortality Among US Adults with Diabetes. Arch. Intern. Med. 163, 1440-1447. doi:10.1001/archinte.163.12.1440

Handy, S. L., Boarnet, M. G., Ewing, R., and Killingsworth, R. E. (2002). How the Built Environment Affects Physical Activity. Am. J. Prev. Med. 23, 64-73. doi:10.1016/S0749-3797(02)00475-0

Handy, S., and McCann, B. (2010). The Regional Response to Federal Funding for Bicycle and Pedestrian Projects. J. Am. Plann. Assoc. 77, 23-38. doi:10.1080/ 01944363.2011.526537

Hanibuchi, T., Kondo, K., Nakaya, T., Shirai, K., Hirai, H., and Kawachi, I. (2012). Does Walkable Mean Sociable? Neighborhood Determinants of Social Capital Among Older Adults in Japan. Health \& Place 18, 229-239. doi:10.1016/ j.healthplace.2011.09.015

Hankey, S., Lindsey, G., and Marshall, J. D. (2017). Population-level Exposure to Particulate Air Pollution during Active Travel: Planning for Low-Exposure, HealthPromoting Cities. Environ. Health Perspect. 125, 527-534. doi:10.1289/ehp442

Houle, J., Doyon, O., Vadeboncoeur, N., Turbide, G., Diaz, A., and Poirier, P. (2011). Innovative Program to Increase Physical Activity Following an Acute Coronary Syndrome: Randomized Controlled Trial. Patient Education Couns. 85, e237-e244. doi:10.1016/j.pec.2011.03.018

Howell, N. A., Tu, J. V., Moineddin, R., Chen, H., Chu, A., Hystad, P., et al. (2019). Interaction between Neighborhood Walkability and Traffic-Related Air Pollution on Hypertension and Diabetes: The CANHEART Cohort. Environ. Int. 132, 104799. doi:10.1016/j.envint.2019.04.070

Howley, P., Scott, M., and Redmond, D. (2009). Sustainability versus Liveability: An Investigation of Neighbourhood Satisfaction. J. Environ. Plann. Management 52, 847-864. doi:10.1080/09640560903083798

Hu, F. B., Sigal, R. J., Rich-Edwards, J. W., Colditz, G. A., Solomon, C. G., Willett, W. C., et al. (1999). Walking Compared with Vigorous Physical Activity and Risk of Type 2 Diabetes in Women. Jama 282, 1433-1439. doi:10.1001/jama.282.15.1433

James, P., Hart, J. E., and Laden, F. (2015). Neighborhood Walkability and Particulate Air Pollution in a Nationwide Cohort of Women. Environ. Res. 142, 703-711. doi:10.1016/j.envres.2015.09.005

James, P., Kioumourtzoglou, M.-A., Hart, J. E., Banay, R. F., Kloog, I., and Laden, F. (2017). Interrelationships between Walkability, Air Pollution, Greenness, and Body Mass Index. Epidemiology 28, 780-788. doi:10.1097/EDE.0000000000000724

Jeffrey, D., Boulangé, C., Giles-Corti, B., Washington, S., and Gunn, L. (2019). Using Walkability Measures to Identify Train Stations with the Potential to Become Transit Oriented Developments Located in Walkable Neighbourhoods. J. Transport Geogr. 76, 221-231. doi:10.1016/j.jtrangeo.2019.03.009

Johansson, M., Hartig, T., and Staats, H. (2011). Psychological Benefits of Walking: Moderation by Company and Outdoor Environment. Appl. Psychol. Heal. Wellbeing 3, 261-280. doi:10.1111/j.1758-0854.2011.01051.x

Jun, H.-J., and Hur, M. (2015). The Relationship between Walkability and Neighborhood Social Environment: The Importance of Physical and Perceived Walkability. Appl. Geogr. 62, 115-124. doi:10.1016/j.apgeog.2015.04.014

Keall, M. D., Shaw, C., Chapman, R., and Howden-Chapman, P. (2018). Reductions in Carbon Dioxide Emissions from an Intervention to Promote Cycling and Walking: A Case Study from New Zealand. Transportation Res. D: Transport Environ. 65, 687-696. doi:10.1016/j.trd.2018.10.004

Kim, E. J., and Kim, H. (2020). Neighborhood Walkability and Housing Prices: A Correlation Study. Sustainability 12, 593. doi:10.3390/su12020593

Koh, P. P., and Wong, Y. D. (2013). Comparing Pedestrians' Needs and Behaviours in Different Land Use Environments. J. Transport Geogr. 26, 43-50. doi:10.1016/j.jtrangeo.2012.08.012

Lamour, Q., Morelli, A. M., and Marins, K. R. d. C. (2019). Improving Walkability in a TOD Context: Spatial Strategies that Enhance Walking in the Belém 
Neighbourhood, in São Paulo, Brazil. Case Stud. Transport Pol. 7, 280-292. doi:10.1016/j.cstp.2019.03.005

Lauf, S., Haase, D., and Kleinschmit, B. (2014). Linkages between Ecosystem Services Provisioning, Urban Growth and Shrinkage - A Modeling Approach Assessing Ecosystem Service Trade-Offs. Ecol. Indicators 42, 73-94. doi:10.1016/j.ecolind.2014.01.028

Lee, S., Lee, C., Nam, J. W., Abbey-Lambertz, M., and Mendoza, J. A. (2020). School Walkability index: Application of Environmental Audit Tool and GIS. J. Transport Health 18, 100880. doi:10.1016/j.jth.2020.100880

Leyden, K. M. (2003). Social Capital and the Built Environment: The Importance of Walkable Neighborhoods. Am. J. Public Health 93, 1546-1551. doi:10.2105/ AJPH.93.9.1546

Lin, L., and Moudon, A. V. (2010). Objective versus Subjective Measures of the Built Environment, Which Are Most Effective in Capturing Associations with Walking?. Health \& Place 16, 339-348. doi:10.1016/j.healthplace.2009.11.002

Litman, T. A. (2003). Economic Value of Walkability. Transportation Res. Rec. 1828, 3-11. doi:10.3141/1828-01

Lo, R. H. (2009). Walkability: what Is it? J. Urbanism: Int. Res. Placemaking Urban Sustainability 2, 145-166. doi:10.1080/17549170903092867

Lue, G., and Miller, E. J. (2019). Estimating a Toronto Pedestrian Route Choice Model Using Smartphone GPS Data. Trav. Behav. Soc. 14, 34-42. doi:10.1016/ j.tbs.2018.09.008

Lukuman, M., Sipan, I., Raji, F., and Aderemi, O. S. (2017). Sustainable Livable Housing: A Review of what Traditional Urban Areas Residents Find Important. Int. J. Built Environ. Sustain. 4. doi:10.11113/ijbes.v4.n3.212

Mackenbach, J. D., Rutter, H., Compernolle, S., Glonti, K., Oppert, J.-M., Charreire, H., et al. (2014). Obesogenic Environments: a Systematic Review of the Association between the Physical Environment and Adult Weight Status, the SPOTLIGHT Project. BMC Public Health 14, 233. doi:10.1186/1471-2458-14-233

Maghelal, P. K., and Capp, C. J. (2011). Walkability: A Review of Existing Pedestrian Indices. J. Urban Reg. Inf. Syst. Assoc. 23, 5-19.

Mamun, M. A. A., and Yuce, M. R. (2019). Sensors and Systems for Wearable Environmental Monitoring toward IoT-Enabled Applications: A Review. IEEE Sensors J. 19, 7771-7788. doi:10.1109/JSEN.2019.2919352

Manaugh, K., and Kreider, T. (2013). What Is Mixed Use? Presenting an Interaction Method for Measuring Land Use Mix. Jtlu 6, 63-72. doi:10.5198/jtlu.v6i1.291

Marquet, O., Floyd, M. F., James, P., Glanz, K., Jennings, V., Jankowska, M. M., et al. (2020). Associations between Worksite Walkability, Greenness, and Physical Activity Around Work. Environ. Behav. 52, 139-163. doi:10.1177/0013916518797165

Marra, A. D., Becker, H., Axhausen, K. W., and Corman, F. (2019). Developing a Passive GPS Tracking System to Study Long-Term Travel Behavior. Transportation Res. C: Emerging Tech. 104, 348-368. doi:10.1016/j.trc.2019.05.006

Marshall, J. D., Brauer, M., and Frank, L. D. (2009). Healthy Neighborhoods: Walkability and Air Pollution. Environ. Health Perspect. 117, 1752-1759. doi:10.1289/ehp.0900595

Martinez, C. A., Carmeli, E., Barak, S., and Stopka, C. B. (2009). Changes in Painfree Walking Based on Time in Accommodating Pain-free Exercise Therapy for Peripheral Arterial Disease. J. Vasc. Nurs. 27, 2-7. doi:10.1016/j.jvn.2008.11.001

Martínez-Bravo, M. d. M., Martínez-del-Río, J., and Antolín-López, R. (2019). Trade-offs Among Urban Sustainability, Pollution and Livability in European Cities. J. Clean. Prod. 224, 651-660. doi:10.1016/j.jclepro.2019.03.110

Masoud, M., Rastbin, S., and Tohidy Ardahaey, F. (2011). Evaluation of Social Capital, Considering Sociability and Walkability in Urban Fabrics: The Case of Isfahan City, Iran. Asian Soc. Sci. 7. doi:10.5539/ass.v7n10p216

McCartney, D. M., and Byrne, D. G. (2020). Optimisation of Vitamin D Status for Enhanced Immuno-protection against Covid-19. Ir Med. J. 113, 58.

McCormack, G. R., Friedenreich, C., Sandalack, B. A., Giles-Corti, B., Doyle-Baker, P. K., and Shiell, A. (2012). The Relationship between Cluster-Analysis Derived Walkability and Local Recreational and Transportation Walking Among Canadian Adults. Health \& Place 18, 1079-1087. doi:10.1016/j.healthplace.2012.04.014

McDonald, N. C., and Aalborg, A. E. (2009). Why Parents Drive Children to School: Implications for Safe Routes to School Programs. J. Am. Plann. Assoc. 75, 331-342. doi:10.1080/01944360902988794

McKenzie, S. (2004). Social Sustainability: Towards Some Definitions. Australia: Hawke Research Institute (UniSA).

Mobily, K. E., Rubenstein, L. M., Lemke, J. H., O'Hara, M. W., and Wallace, R. B. (1996). Walking and Depression in a Cohort of Older Adults: The Iowa 65+ Rural Health Study. J. Aging Phys. Act. 4, 119-135. doi:10.1123/japa.4.2.119
Mohamed, A. A. K., Abdelmonem, M. G., and Selim, G. (2016). Understanding Walkability in the Libyan Urban Space: Policies, Perceptions and Smart Design for Sustainable Tripoli. World Acad. Sci. Eng. Technol. Int. J. Civil, Environ. Struct. Constr. Archit. Eng. 10, 1602-1610.

Mooney, S. J., Hurvitz, P. M., Moudon, A. V., Zhou, C., Dalmat, R., and Saelens, B. E. (2020). Residential Neighborhood Features Associated with Objectively Measured Walking Near home: Revisiting Walkability Using the Automatic Context Measurement Tool (ACMT). Health \& Place 63, 102332. doi:10.1016/ j.healthplace.2020.102332

Moura, F., Cambra, P., and Gonçalves, A. B. (2017). Measuring Walkability for Distinct Pedestrian Groups with a Participatory Assessment Method: A Case Study in Lisbon. Landscape Urban Plann. 157, 282-296. doi:10.1016/ j.landurbplan.2016.07.002

Nakayoshi, M., Kanda, M., Shi, R., and de Dear, R. (2014). Outdoor thermal Physiology along Human Pathways: a Study Using a Wearable Measurement System. Int. J. Biometeorol. 59, 503-515. doi:10.1007/s00484-014-0864-y

Neves, A., and Brand, C. (2019). Assessing the Potential for Carbon Emissions Savings from Replacing Short Car Trips with Walking and Cycling Using a Mixed GPS-Travel Diary Approach. Transportation Res. A: Pol. Pract. 123, 130-146. doi:10.1016/j.tra.2018.08.022

Newell, R., Dale, A., and Roseland, M. (2018). Climate Action Co-benefits and Integrated Community Planning: Uncovering the Synergies and Trade-Offs. The Int. J. Clim. Change Impacts Responses 10, 1-23. doi:10.18848/1835-7156/cgp/v10i04/1-23

Nikolopoulou, M., and Steemers, K. (2003). Thermal comfort and Psychological Adaptation as a Guide for Designing Urban Spaces. Energy and Buildings 35, 95-101. doi:10.1016/s0378-7788(02)00084-1

Noland, R. B., Weiner, M. D., DiPetrillo, S., and Kay, A. I. (2017). Attitudes towards Transit-Oriented Development: Resident Experiences and Professional Perspectives. J. Transport Geogr. 60, 130-140. doi:10.1016/j.jtrangeo.2017.02.015

Novaković, M., Krevel, B., Rajkovič, U., Vižintin Cuderman, T., Janša Trontelj, K., Fras, Z., et al. (2019). Moderate-pain versus Pain-free Exercise, Walking Capacity, and Cardiovascular Health in Patients with Peripheral Artery Disease. J. Vasc. Surg. 70, 148-156. doi:10.1016/j.jvs.2018.10.109

O'Connor, S. R., Tully, M. A., Ryan, B., Bleakley, C. M., Baxter, G. D., Bradley, J. M., et al. (2015). Walking Exercise for Chronic Musculoskeletal Pain: Systematic Review and Meta-Analysis. Arch. Phys. Med. Rehabil. 96, 724-734. E3. doi:10.1016/j.apmr.2014.12.003

Park, S., Deakin, E., and Jang, K. (2015). Can Good Walkability Expand the Size of Transit-Oriented Developments?. Transportation Res. Rec. 2519, 157-164. doi:10.3141/2519-17

Pereira Neto, E. A., Bittar, S. T., Silva, J. C. G. d., Pfeiffer, P. A. S., Santos, H. H., and de Sousa, M. d. S. C. (2018). Walking with Blood Flow Restriction Improves the Dynamic Strength of Women with Osteoporosis. Rev. Bras Med. Esporte 24, 135-139. doi:10.1590/1517-869220182402175290

Pigliautile, I., D’Eramo, S., and Pisello, A. L. (2021). Intra-urban Microclimate Mapping for Citizens' Wellbeing: Novel Wearable Sensing Techniques and Automatized Data-Processing. J. Clean. Prod. 279, 123748. doi:10.1016/ j.jclepro.2020.123748

Pinelo Silva, J., and Akleh, A. Z. (2018). Investigating the Relationships between the Built Environment, the Climate, Walkability and Physical Activity in the Arabian Peninsula: The Case of Bahrain. Cogent Soc. Sci. 4, 1502907-1502921. doi:10.1080/23311886.2018.1502907

Pivo, G., and Fisher, J. D. (2011). The Walkability Premium in Commercial Real Estate Investments. Real Estate Econ. 39, 185-219. doi:10.1111/j.15406229.2010.00296.x

Poom, A., and Ahas, R. (2016). How Does the Environmental Load of Household Consumption Depend on Residential Location?. Sustainability 8, 799. doi:10.3390/su8090799

Rahman, M., and Nahiduzzaman, K. (2019). Examining the Walking Accessibility, Willingness, and Travel Conditions of Residents in Saudi Cities. Ijerph 16, 545. doi:10.3390/ijerph16040545

Rakha, T. (2015). Towards Comfortable and Walkable Cities: Spatially Resolved Outdoor Thermal Comfort Analysis Linked to Travel Survey-Based Human Activity Schedules. MIT.

Rauterkus, S. Y., and Miller, N. (2011). Residential Land Values and Walkability. J. Sustainable Real Estate 3, 23-43. doi:10.1080/10835547.2011.12091815

Rayan, L. (2013). Informal Ties, Social Capital and Development: Popular Committees in Egypt, a Case Study post-25th of January Revolution. 
Rodríguez-Algeciras, J., Tablada, A., and Matzarakis, A. (2018). Effect of Asymmetrical Street Canyons on Pedestrian thermal comfort in Warm-Humid Climate of Cuba. Theor. Appl. Climatol. 133, 663-679. doi:10.1007/s00704-017-2204-8

Roe, J., and Aspinall, P. (2011). The Restorative Benefits of Walking in Urban and Rural Settings in Adults with Good and Poor Mental Health. Health \& Place 17, 103-113. doi:10.1016/j.healthplace.2010.09.003

Ruth, M., and Franklin, R. S. (2014). Livability for All? Conceptual Limits and Practical Implications. Appl. Geogr. 49, 18-23. doi:10.1016/j.apgeog.2013.09.018

Sabzali Yameqani, A., and Alesheikh, A. A. (2019). Predicting Subjective Measures of Walkability index from Objective Measures Using Artificial Neural Networks. Sustainable Cities Soc. 48, 101560. doi:10.1016/j.scs.2019.101560

Saelens, B. E., Sallis, J. F., Black, J. B., and Chen, D. (2003). Neighborhood-based Differences in Physical Activity: an Environment Scale Evaluation. Am. J. Public Health 93, 1552-1558. doi:10.2105/ajph.93.9.1552

Saint-Maurice, P. F., Troiano, R. P., Bassett, D. R., Graubard, B. I., Carlson, S. A., Shiroma, E. J., et al. (2020). Association of Daily Step Count and Step Intensity with Mortality Among US Adults. Jama 323, 1151-1160. doi:10.1001/jama.2020.1382

Samarasekara, G. N., Fukahori, K., and Kubota, Y. (2011). Environmental Correlates that Provide Walkability Cues for Tourists: An Analysis Based on Walking Decision Narrations. Environ. Behav. 43, 501-524. doi:10.1177/0013916510379350

Sarkar, C., Webster, C., and Gallacher, J. (2018). Neighbourhood Walkability and Incidence of Hypertension: Findings from the Study of 429,334 UK Biobank Participants. Int. J. Hyg. Environ. Health 221, 458-468. doi:10.1016/j.ijheh.2018.01.009

Shaaban, K., Muley, D., and Elnashar, D. (2018). Evaluating the Effect of Seasonal Variations on Walking Behaviour in a Hot Weather Country Using Logistic Regression. Int. J. Urban Sci. 22, 382-391. doi:10.1080/12265934.2017.1403363

Shaaban, K., Muley, D., and Elnashar, D. (2017). Temporal Variation in Walking Behavior: An Empirical Study. Case Stud. Transport Pol. 5, 671-680. doi:10.1016/j.cstp.2017.07.001

Shaheen, S., and Chan, N. (2016). Mobility and the Sharing Economy: Potential to Facilitate the First- and Last-Mile Public Transit Connections. Built Environ. 42, 573-588. doi:10.2148/benv.42.4.573

Shamsuddin, S., Hassan, N. R. A., and Bilyamin, S. F. I. (2012). Walkable Environment in Increasing the Liveability of a City. Proced. - Soc. Behav. Sci. 50, 167-178. doi:10.1016/j.sbspro.2012.08.025

Sharmin, T., and Steemers, K. (2013). "Effect of Canyon Geometry on Outdoor Thermal Comfort," in PLEA2013 - 29th International Conference Proceedings: Sustainable Architecture for a Renewable Future, Munich, Germany, 10-12 September 2013.

Shashank, A., and Schuurman, N. (2019). Unpacking Walkability Indices and Their Inherent Assumptions. Health \& Place 55, 145-154. doi:10.1016/ j.healthplace.2018.12.005

Silva, J. P. (2017). Solar Radiation and Street Temperature as Function of Street Orientation. An Analysis of the Status Quo and Simulation of Future Scenarios towards Sustainability in Bahrain. E3S Web of Conferences 23, 2002. doi:10.1051/e3sconf/20172302002

Simons, E., Dell, S. D., Moineddin, R., and To, T. (2018). Associations between Neighborhood Walkability and Incident and Ongoing Asthma in Children. Ann. ATS 15, 728-734. doi:10.1513/AnnalsATS.201708-693OC

Siqueira, G. d., Adeel, A., Pasha, P., Balushi, A. A., and Shah, S. A. R. (2021). Sustainable Transportation and Policy Development: A Study for Impact Analysis of Mobility Patterns and Neighborhood Assessment of Walking Behavior. Sustainability 13, 1871. doi:10.3390/su13041871

Sisiopiku, V. P., and Akin, D. (2003). Pedestrian Behaviors at and Perceptions towards Various Pedestrian Facilities: an Examination Based on Observation and Survey Data. Transportation Res. F: Traffic Psychol. Behav. 6, 249-274. doi:10.1016/j.trf.2003.06.001

Smith, T. C., Wingard, D. L., Smith, B., Kritz-Silverstein, D., and Barrett-Connor, E. (2007). Walking Decreased Risk of Cardiovascular Disease Mortality in Older Adults with Diabetes. J. Clin. Epidemiol. 60, 309-317. doi:10.1016/ j.jclinepi.2006.06.013

Southworth, M. (2005). Designing the Walkable City. J. Urban Plann. Dev. 131, 246-257. doi:10.1061/(asce)0733-9488(2005)131:4(246)

Stangl, P. (2012). The Pedestrian Route Directness Test: A New Level-Of-Service Model. URBAN Des. Int. 17, 228-238. doi:10.1057/udi.2012.14

Suarez-Balcazar, Y., Early, A. R., Garcia, C., Balcazar, D., Arias, D. L., and Morales, M. (2020). Walkability Safety and Walkability Participation: a Health Concern. Health Educ. Behav. 47, 430-438. doi:10.1177/1090198120903256

Suhrcke, M., Nugent, R. A., Stuckler, D., and Rocco, L. (2006). Chronic Disease: An Economic Perspective. London, UK: London Oxford Health Alliance.
Taleghani, M. (2018). Outdoor thermal comfort by Different Heat Mitigation Strategies- A Review. Renew. Sustainable Energ. Rev. 81, 2011-2018. doi:10.1016/j.rser.2017.06.010

Timperio, A., Crawford, D., Telford, A., and Salmon, J. (2004). Perceptions about the Local Neighborhood and Walking and Cycling Among Children. Prev. Med. 38, 39-47. doi:10.1016/j.ypmed.2003.09.026

Tomalty, R., and Mallach, A. (2015). "Differences in Livability and Sustainability," in America's Urban Future (Washington, DC: Island Press), 51-70. doi:10.5822/ 978-1-61091-597-7_4

Tribe, M. A. (1976). The Interrelations of Urban and National Planning-A Comment. Urban Stud. 13, 201-204. doi:10.1080/00420987620080351

Tucker, C. J. (1979). Red and Photographic Infrared Linear Combinations for Monitoring Vegetation. Remote Sensing Environ. 8, 127-150. doi:10.1016/00344257(79)90013-0

van den Berg, P., Sharmeen, F., and Weijs-Perrée, M. (2017). On the Subjective Quality of Social Interactions: Influence of Neighborhood Walkability, Social Cohesion and Mobility Choices. Transportation Res. Part A: Pol. Pract. 106, 309-319. doi:10.1016/j.tra.2017.09.021

Van den Heuvel, E. G. H. M., Van Schoor, N., De Jongh, R. T., Visser, M., and Lips, P. (2013). Cross-sectional Study on Different Characteristics of Physical Activity as Determinants of Vitamin D Status; Inadequate in Half of the Population. Eur. J. Clin. Nutr. 67, 360-365. doi:10.1038/ejcn.2013.22

Villaveces, A., Nieto, L. A., Ortega, D., Ríos, J. F., Medina, J. J., Gutiérrez, M. I., et al. (2012). Pedestrians' Perceptions of Walkability and Safety in Relation to the Built Environment in Cali, Colombia, 2009-10. Inj. Prev. 18, 291-297. doi:10.1136/injuryprev-2011-040223

Yamagata, Y., Murakami, D., Wu, Y., Yang, P. P.-J., Yoshida, T., and Binder, R. (2019). Bigdata Analysis for Carbon Emission Reduction from Cars: Towards Walkable green Smart Community. Energ. Proced. 158, 4292-4297. doi:10.1016/j.egypro.2019.01.795

Yao, J., Yang, F., Zhuang, Z., Shao, Y., and Yuan, P. F. (2018). The Effect of Personal and Microclimatic Variables on Outdoor thermal comfort: A Field Study in a Cold Season in Lujiazui CBD, Shanghai. Sustainable Cities Soc. 39, 181-188. doi:10.1016/j.scs.2018.02.025

Yencha, C. (2019). Valuing Walkability: New Evidence from Computer Vision Methods. Transportation Res. Part A: Pol. Pract. 130, 689-709. doi:10.1016/j.tra.2019.09.053

Yoo, C., and Lee, S. (2016). Neighborhood Built Environments Affecting Social Capital and Social Sustainability in Seoul, Korea. Sustainability 8, 1346. doi:10.3390/su8121346

Yoshida, T., and Tanaka, K. (2005). Land-use Diversity index: a New Means of Detecting Diversity at Landscape Level. Landscape Ecol. Eng. 1, 201-206. doi:10.1007/s11355-005-0022-0

Zhang, J., Tan, P. Y., Zeng, H., and Zhang, Y. (2019). Walkability Assessment in a Rapidly Urbanizing City and its Relationship with Residential Estate Value. Sustainability 11, 2205. doi:10.3390/su11082205

Zhu, X., and Lee, C. (2008). Walkability and Safety Around Elementary Schools. Am. J. Prev. Med. 34, 282-290. doi:10.1016/j.amepre.2008.01.024

Zook, J. B., Lu, Y., Glanz, K., and Zimring, C. (2012). Design and Pedestrianism in a Smart Growth Development. Environ. Behav. 44, 216-234. doi:10.1177/0013916511402060

Zuniga-Teran, A. A., Orr, B. J., Gimblett, R. H., Chalfoun, N. V., Marsh, S. E., Guertin, D. P., et al. (2017). Designing Healthy Communities: Testing the Walkability Model. Front. Architectural Res. 6, 63-73. doi:10.1016/j.foar.2016.11.005

Conflict of Interest: The authors declare that the research was conducted in the absence of any commercial or financial relationships that could be construed as a potential conflict of interest.

Publisher's Note: All claims expressed in this article are solely those of the authors and do not necessarily represent those of their affiliated organizations, or those of the publisher, the editors and the reviewers. Any product that may be evaluated in this article, or claim that may be made by its manufacturer, is not guaranteed or endorsed by the publisher.

Copyright (ㄷ 2021 Baobeid, Koç and Al-Ghamdi. This is an open-access article distributed under the terms of the Creative Commons Attribution License (CC BY). The use, distribution or reproduction in other forums is permitted, provided the original author(s) and the copyright owner(s) are credited and that the original publication in this journal is cited, in accordance with accepted academic practice. No use, distribution or reproduction is permitted which does not comply with these terms. 